\title{
Deep levels in iron doped n- and p-type 4H-SiC
}

\author{
Franziska Beyer, Carl Hemmingsson, Stefano Leone, Y.-C. Lin, Henrik Gällström,
} Anne Henry and Erik Janzén

\section{Linköping University Post Print}

N.B.: When citing this work, cite the original article.

Original Publication:

Franziska Beyer, Carl Hemmingsson, Stefano Leone, Y.-C. Lin, Henrik Gällström, Anne Henry and Erik Janzén, Deep levels in iron doped n- and p-type 4H-SiC, 2011, Journal of Applied Physics, (110), 123701-1-123701-5.

http://dx.doi.org/10.1063/1.3669401

Copyright: American Institute of Physics (AIP) http://www.aip.org/

Postprint available at: Linköping University Electronic Press http://urn.kb.se/resolve?urn=urn:nbn:se:liu:diva-70352 


\title{
Deep levels in iron doped $n$ - and p-type $4 \mathrm{H}-\mathrm{SiC}$
}

\author{
F. C. Beyer, ${ }^{\text {a) }}$ C. G Hemmingsson, S. Leone, Y.-C. Lin, A. Gällström, A. Henry, \\ and E. Janzén \\ Department of Physics, Chemistry and Biology, Linköping University, SE-581 83 Linköping, Sweden
}

(Received 18 July 2011; accepted 12 November 2011; published online 16 December 2011)

\begin{abstract}
Deep levels were detected in Fe-doped $n$ - and $p$-type $4 \mathrm{H}$-SiC using deep level transient spectroscopy (DLTS). One defect level $\left(E_{C}-0.39 \mathrm{eV}\right)$ was detected in $n$-type material. DLTS spectra of $p$-type $4 \mathrm{H}-\mathrm{SiC}$ show two dominant peaks $\left(E_{V}+0.97 \mathrm{eV}\right.$ and $\left.E_{V}+1.46 \mathrm{eV}\right)$. Secondary ion mass spectrometry measurements confirm the presence of $\mathrm{Fe}$ in both $n$ - and $p$-type $4 \mathrm{H}$-SiC epitaxial layers. The majority of the capture process for $\mathrm{Fe} 1, \mathrm{Fe} 2$, and $\mathrm{Fe} 3$ is multi-phonon emission assisted. These three detected peaks are suggested to be related to Fe. (C) 2011 American Institute of Physics. [doi:10.1063/1.3669401]
\end{abstract}

\section{INTRODUCTION}

Transition metal (TM) incorporation, especially Vanadium doping, ${ }^{1,2}$ is often used to obtain semi-insulating (SI) $\mathrm{SiC}$. Recent reports show that iron (Fe) also may be a possible candidate to obtain $\mathrm{SI} \mathrm{SiC}{ }^{3} \mathrm{Fe}$ as possible residual impurity in SiC may affect the minority carrier lifetime. Besides the possibility to fabricate SI material, TMs, especially manganese $(\mathrm{Mn})$ and iron (Fe), may also be used to obtain diluted magnetic semiconductors. ${ }^{4-7}$

Using electron spin resonance, Baranov et al. ${ }^{8}$ tried to identify the electronic states of $\mathrm{Fe}$ in $6 \mathrm{H}-\mathrm{SiC}$, which may be responsible for its SI property. Only very few electrical investigations on Fe-related levels in $\mathrm{SiC}$ have been presented. $^{9,10}$ The authors therein observed deep levels in Fe-implanted Al-doped $p$-type $4 \mathrm{H}$ - and 3C-SiC using deep level transient spectroscopy (DLTS).

In case of silicon $(\mathrm{Si}), \mathrm{Fe}$ is one of the most studied impurities. It is present as $\mathrm{Fe}_{i}$, but also as complex with other impurities. Already at room temperatures, Fe diffuses easily and pairs with shallow acceptors. ${ }^{11}$ In $n$-type $\mathrm{Si}, \mathrm{Fe}$ forms electrically inactive complexes. ${ }^{12,13}$ However, Kitagawa et $a l .{ }^{12}$ observed one deep level in $n$-type $\mathrm{Si}$ assigned to an intermediate state prior to iron-related complex formation. Istratov et al. ${ }^{13}$ discussed possible $\mathrm{Fe}$ and Fe-acceptor (with mainly $\mathrm{B}, \mathrm{Al}, \mathrm{Ga}$, and In) pairs with metastable behavior in $p$-type $\mathrm{Si}$. In the lower band gap, two levels related to $\mathrm{Fe}$ were detected by DLTS both in the case of B- and Al-doping. For B-doped $p$-type $\mathrm{Si}^{13}$ there are three levels detected after Fe incorporation using DLTS: one interstitial $\mathrm{Fe}\left(F e_{i}\right)$ level and two Fe-B pair levels. Additionally, $\mathrm{Fe}_{i}$ as well as Fe-B pairs are known to be very efficient recombination centers in $p$-type $\mathrm{Si}^{13,14}$

In our study, we have electrically characterized Fe-doped $n$ - and $p$-type $4 \mathrm{H}$-SiC epitaxial layers using DLTS and minority carrier transient spectroscopy (MCTS) to detect possible Fe-related defect levels.

\footnotetext{
a) Author to whom correspondence should be addressed. Electronic mail: fbeyer@ifm.liu.se.
}

\section{EXPERIMENTAL DETAILS}

The epitaxial $n$ - and $p-4 \mathrm{H}-\mathrm{SiC}$ layers were grown on highly doped $n$ - and $p-4 \mathrm{H}-\mathrm{SiC}$ substrates, respectively, using a chloride-based $(\mathrm{HCl})$ chemical vapor deposition (CVD) growth process. ${ }^{15}$ The epitaxial layers were unintentionally doped. The moderate $n$ - and $p$-doping was obtained by choosing appropriate $\mathrm{C} / \mathrm{Si}$ ratios as well as suitable growth rates as discussed in Ref. 16. $P$-type doping was obtained from the presence of boron (B) in the graphite susceptor and from earlier performed doping studies. ${ }^{17}$ The Fe doping was achieved by leaving small metallic flakes of Fe (99.99\%) directly on the substrate and in the upstream part of the susceptor. Prior to the metal contact deposition, the samples were chemically cleaned and briefly dipped in hydrofluoric acid to remove the native oxide. For the $n$-type samples, $\mathrm{Ni}$ (about $1000 \AA$ ) was thermally deposited onto the epitaxial layer to form Schottky contacts, whereas the ohmic contact was established by conductive silver paint to the highly doped substrate. In case of $p$-type samples, Ti (about $1000 \AA$ ) was thermally deposited as rectifying contact and an alloy of

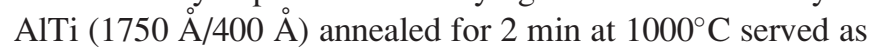
ohmic contact to the backside. The Schottky diodes were characterized by current-voltage measurements ensuring the rectifying behavior and by capacitance voltage $(\mathrm{CV})$ measurements determining the net doping concentrations, $N_{d}-N_{a}$ or $N_{a}-N_{d}$, respectively, both at room temperature. CV measurements revealed a homogenous doping with net doping concentrations in the low to mid $10^{15} \mathrm{~cm}^{-3}$ range for the $n$ - and $p$-doped Fe layers. DLTS was applied to investigate the deep levels in the temperature range 85 to $700 \mathrm{~K}$ for $n$-type layers and above the freezing out temperature for $p$-type layers $(T>200 \mathrm{~K})$. If not mentioned differently, the following DLTS parameters were used for both doping types: filling pulse width of $10 \mathrm{~ms}$ and a filling pulse height of $10 \mathrm{~V}$. The steady reverse bias was $V_{r}=-10 \mathrm{~V}$. Minority carrier injection was studied at a constant reverse bias of $V_{r}=10 \mathrm{~V}$ using a $200 \mathrm{~ms}$ long UV laser pulse ( $\mathrm{Ar}^{+}$, multiline 351-355 nm). The laser spot exceeded the contact diameter, thus excess carrier diffusion enhanced by the applied electric field enabled the capture of minority carriers in the depletion region, since 

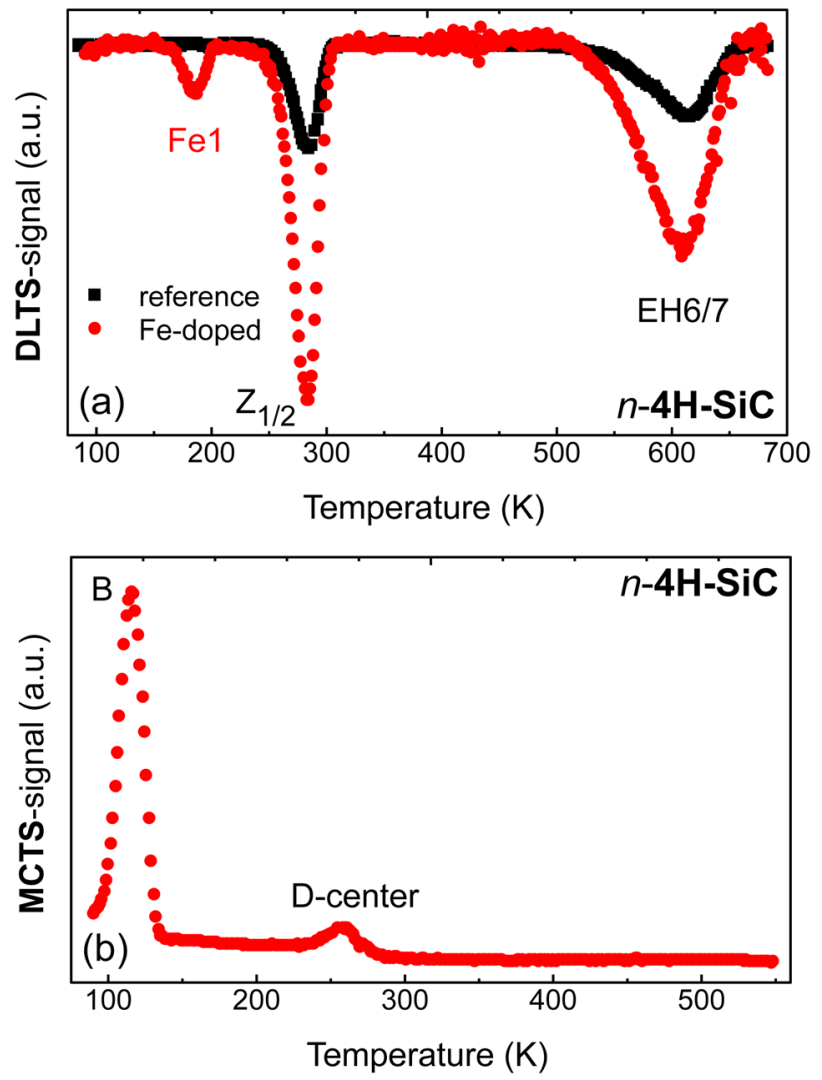

FIG. 1. (Color online) DLTS/MCTS spectra of $n$-type 4H-SiC samples: (a) DLTS spectra of Fe doped (circles) and reference (squares) material, rate window $2.8 \mathrm{~s}^{-1}$; DLTS parameters: $t_{p}=10 \mathrm{~ms}, V_{r}=-10 \mathrm{~V}$, and $V_{p}=10 \mathrm{~V}$. (b) MCTS spectrum of Fe-doped $n$-type $4 \mathrm{H}-\mathrm{SiC}$; MCTS parameters: $t_{p}=200 \mathrm{~ms}, V_{r}=-10 \mathrm{~V}$, UV excitation: multiline $\mathrm{Ar}^{+}$-laser.

the contacts were not semitransparent. Front-side illumination was used, although the DLTS-setup does not allow backside illumination; therefore both minority and majority carriers are present in the depletion region during illumination. Furthermore, direct photoionization of the traps due to illumination may occur. ${ }^{18}$ Therefore, the signal of minority traps in the MCTS spectrum may be decreased or even not detectable. The capacitance transients were evaluated using a conventional boxcar technique. Secondary ion mass spectrometry (SIMS) measurements were performed using the oxygen primary ion beam for analysis. ${ }^{19}$

\section{RESULTS AND DISCUSSION}

\section{A. Fe in n-type $4 \mathrm{H}-\mathrm{SiC}$}

In Figure 1(a), a DLTS spectrum of Fe-doped n-type $4 \mathrm{H}-\mathrm{SiC}$ is compared to a spectrum of a reference sample without $\mathrm{Fe}$ incorporation. In both spectra, the well-known intrinsic defects $Z_{1 / 2}$ (Ref. 20) and EH6/7 (Ref. 21) were observed. The defect concentrations of the intrinsic levels are in the low $10^{13} \mathrm{~cm}^{-3}$ range for the reference and slightly higher for the Fe-doped sample, which may indicate that we induce more intrinsic defects by disturbing the $\mathrm{SiC}$ lattice with the doping. In addition to the intrinsic deep levels, an additional peak, called $\mathrm{Fe} 1$ with an activation energy of $E_{a}=E_{C}-0.39 \mathrm{eV}$, was observed after doping the epitaxial layer with Fe. The measured electron capture cross section will be discussed separately later-on. The Fe1 peak did not show any shift in peak temperature by varying the electric field strength over a range of $16-36 \mathrm{kV} / \mathrm{cm}$. The absence of field dependence ${ }^{22}$ for such relatively small applied field strength range cannot give any definite conclusions about the charge state of the Fe1.

In the MCTS spectra (Fig. 1(b)), only the boron related peaks B $\left(E_{V}+0.27 \mathrm{eV}\right)$ (Ref. 25) and the D-center $\left(E_{V}+0.62 \mathrm{eV}\right)($ Ref. 25) were observed. The evaluation of the $\mathrm{B}$ concentration is uncertain, since it exceeds the low concentration approximation limit $\left(N_{t} \ll N_{d}\right)$. The electronic properties of all peaks, either intrinsic or extrinsic are summarized in Table I.

SIMS analysis, see Table II, revealed the presence of boron $\left([\mathrm{B}]=8.9 \times 10^{14} \mathrm{~cm}^{-3}\right)$ and Fe in the studied $n$-type material with a concentration of $[\mathrm{Fe}]=6.5 \times 10^{14} \mathrm{~cm}^{-3}$. The SIMS detected total Fe-concentration is about 2 orders of magnitude higher than the concentration of the electrically active $\mathrm{Fe}$ defect level $\mathrm{Fe} 1$ as determined by DLTS $\left(N_{t}(\mathrm{Fe} 1)=7.6 \times 10^{12} \mathrm{~cm}^{-3}\right)$. This indicates that Fe in $n$-type material forms electrically inactive complexes.

Recently, it was shown that no Fe-related peaks were detected in Fe-implanted $\mathrm{N}$-doped $\mathrm{SiC}^{9}$. The authors present a DLTS spectrum of $n$-type $\mathrm{SiC}$ after Fe-implantation and annealing at $1600{ }^{\circ} \mathrm{C}$. They observe a peak similar to the $\mathrm{Fe} 1$ besides other intrinsic deep levels and the authors relate this peak to EH1. However, EH1 always occurs in conjunction with EH3, which was not detected. EH1 and EH3 are assigned to the same defect but different charge states. ${ }^{26,27}$

TABLE I. Properties of the Fe-peaks and intrinsic levels: $E_{a}$ and $\sigma$ are obtained from Arrhenius plots $\left(\ln \left(e / T^{2}\right)\right.$ versus $\left.1000 / T\right)$, whereas $\sigma_{\text {meas }}$ from DLTS measurements with different $t_{p}$ and $N_{t}$ from the DLTS peak amplitudes.

\begin{tabular}{|c|c|c|c|c|c|}
\hline & Peak & $E_{a}(\mathrm{eV})$ & $\sigma\left(\mathrm{cm}^{2}\right)$ & $\sigma_{\text {meas }}\left(\mathrm{cm}^{2}\right)$ & $N_{t}\left(\mathrm{~cm}^{-3}\right)$ \\
\hline \multirow[t]{6}{*}{$n$-type } & Fe1 & $E_{C}-0.39$ & $2 \times 10^{-15}$ & $3.9 \times 10^{-16} \exp \left(-0.038 \mathrm{eV} / k_{B} T\right)$ & $7.6 \times 10^{12}$ \\
\hline & $Z_{1 / 2}$ & $E_{C}-0.67$ & $2 \times 10^{-14}$ & $\mathrm{Z}_{1}^{-}: 1.71 \times 10^{-15} \exp \left(-0.065 \mathrm{eV} / k_{B} T\right)^{\mathrm{a}}$ & $3.2 \times 10^{13}$ \\
\hline & & & & $\mathrm{Z}_{2}^{-}: 1.31 \times 10^{-15} \exp \left(-0.080 \mathrm{eV} / k_{B} T\right)^{\mathrm{a}}$ & \\
\hline & EH6/7 & $E_{C}-1.51$ & $1 \times 10^{-14}$ & $\left(5.3 \times 10^{-15}\right)^{\mathrm{b}}$ & $2.1 \times 10^{13}$ \\
\hline & $\mathrm{B}$ & $E_{V}+0.29$ & $3 \times 10^{-13}$ & & $\approx 5 \times 10^{14}$ \\
\hline & D-center & $E_{V}+0.73$ & $5 \times 10^{-12}$ & & $6.3 \times 10^{13}$ \\
\hline \multirow[t]{2}{*}{$p$-type } & $\mathrm{Fe} 2$ & $E_{V}+1.46$ & $3 \times 10^{-14}$ & $3.8 \times 10^{-17} \exp \left(-0.131 \mathrm{eV} / k_{B} T\right)$ & $2.2 \times 10^{14}$ \\
\hline & $\mathrm{Fe} 3$ & $E_{V}+0.97$ & $7 \times 10^{-16}$ & $1.5 \times 10^{-18} \exp \left(-0.180 \mathrm{eV} / k_{B} T\right)$ & $1.7 \times 10^{14}$ \\
\hline
\end{tabular}

${ }^{\mathrm{a}}$ Reference 23.

${ }^{\mathrm{b}}$ Reference 24. 
TABLE II. Net doping concentration $N_{d}-N_{a} / N_{a}-N_{d}$, defect concentrations $N_{t}$ from DLTS measurements in comparison to concentrations obtained from SIMS analysis.

\begin{tabular}{|c|c|c|c|c|c|c|}
\hline & Peak & $N_{d}-N_{a} / N_{a}-N_{d}\left(\mathrm{~cm}^{-3}\right)$ & $N_{t}\left(\mathrm{~cm}^{-3}\right)$ & SIMS: $\mathrm{Fe}\left(\mathrm{cm}^{-3}\right)$ & SIMS: $\mathrm{B}\left(\mathrm{cm}^{-3}\right)$ & SIMS: $\mathrm{Al}\left(\mathrm{cm}^{-3}\right)$ \\
\hline$n$-type & Fe1 & $1.8 \times 10^{15}$ & $7.6 \times 10^{12}$ & $6.5 \times 10^{14}$ & $8.9 \times 10^{14}$ & $<5 \times 10^{13}$ \\
\hline \multirow[t]{3}{*}{$p$-type } & $\mathrm{Fe} 2$ & & $2.2 \times 10^{14}$ & & & \\
\hline & & $5.2 \times 10^{15}$ & & $6.2 \times 10^{14}$ & $1.3 \times 10^{15}$ & $<5 \times 10^{13}$ \\
\hline & $\mathrm{Fe} 3$ & & $1.7 \times 10^{14}$ & & & \\
\hline
\end{tabular}

Furthermore, the reported peak was present after an annealing step of $1600^{\circ} \mathrm{C}$. EH1 and EH3 should be annihilated at these temperatures as shown by several groups. $^{26-29}$ We therefore suggest that the presented EH1 in Ref. 9 is the same as our Fe1 level, which is likely a Fe-related defect.

\section{B. Fe in p-type $4 \mathrm{H}-\mathrm{SiC}$}

For the Fe-doped unintentionally $p$-type $4 \mathrm{H}-\mathrm{SiC}$ epitaxial layer, DLTS spectra of varying pulse widths $\left(t_{p}=5 \mu \mathrm{s}\right.$ (rhombi), $10 \mathrm{~ms}$ (circles), $200 \mathrm{~ms}$ (triangles)) are presented in Figure 2. Two peaks, labeled $\mathrm{Fe} 2$ and $\mathrm{Fe} 3$, are dominant in the spectra with activation energies of $E_{V}+1.46 \mathrm{eV}$ and $E_{V}+0.97 \mathrm{eV}$, respectively. The Fe 2 peak may be composed of several defect levels, since its shape is very asymmetric for all pulse widths and a distinct shoulder is visible at the low temperature side for the longest pulse width. The electronic properties of $\mathrm{Fe} 2$ and $\mathrm{Fe} 3$ are summarized in Table I. The hole capture cross sections were investigated using varying DLTS filling pulse width. The results are also displayed in Table I and will be further discussed in the following section. Earlier DLTS investigations on as-grown $p$-type $4 \mathrm{H}-\mathrm{SiC}$ (Refs. 30-32) revealed several defect levels in the lower half of the $\mathrm{SiC}$ band gap. Danno et al. ${ }^{31,32}$ observed $\mathrm{P} 1\left(E_{V}+1.49 \mathrm{eV}\right)$ and $\mathrm{HK} 4\left(E_{V}+1.44 \mathrm{eV}\right)$, which are located close to our detected $\mathrm{Fe} 2\left(E_{V}+1.46 \mathrm{eV}\right)$ peak. P1 and HK4 are suggested to have the same origin. ${ }^{33}$ The activation energy of $\mathrm{h} 2\left(E_{V}+0.96 \mathrm{eV}\right)$ reported by Han et $a l .{ }^{30}$ in p-doped $4 \mathrm{H}-\mathrm{SiC}$ is similar to one of our peaks, denoted $\mathrm{Fe} 3\left(E_{V}+0.97 \mathrm{eV}\right)$. Although the activation energies were

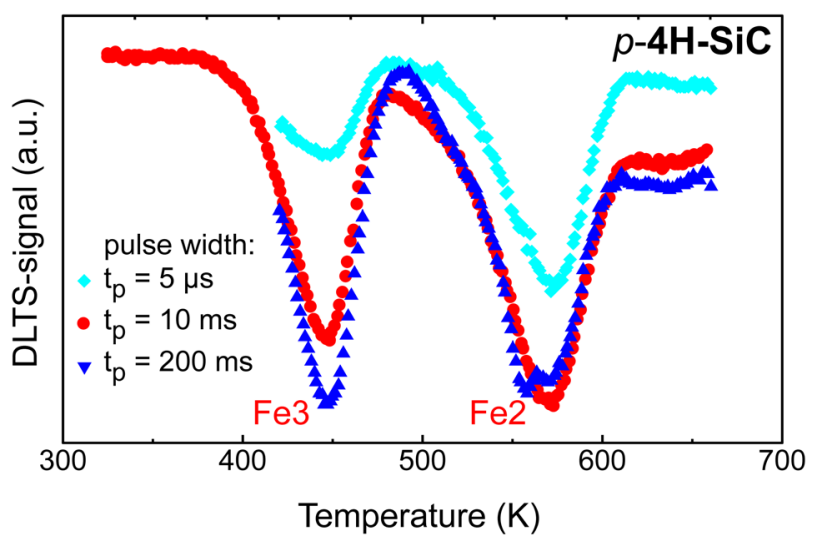

FIG. 2. (Color online) DLTS spectra of Fe-doped $p$-type 4H-SiC samples with varying DLTS pulse lengths $t_{p}=5 \mu \mathrm{s}$ (rhombi), $10 \mathrm{~ms}$ (circles), $200 \mathrm{~ms}$ (triangles); rate window $2.8 \mathrm{~s}^{-1}$; DLTS parameters: $V_{r}=-10 \mathrm{~V}$ and $V_{p}=10 \mathrm{~V}$. similar, the actual emission rates were very different. The detected peaks must therefore have a different origin from the reported ones and are likely related to the Fe-doping.

Surprisingly, no levels, such as $\mathrm{Fe} 2$ or $\mathrm{Fe} 3$, were detected in the MCTS spectrum (Fig. 1(b)) of the n-type sample at higher energies. This indicates that $\mathrm{Fe} 2$ and $\mathrm{Fe} 3$ are either not present in $n$-type material or that their capture rates are unfavorable, since both electrons and holes may be present in the space charge region using front-side illumination.

Table II shows doping and defect concentrations obtained from CV, DLTS, and SIMS. SIMS analysis confirms the incorporation of $\mathrm{Fe}$ atoms in the $\mathrm{SiC}$ layer. It should be mentioned that the different measurements were not taken exactly at the same positions. Therefore and due to an inhomogeneous incorporation of impurities, some discrepancies of the values are expected. The detected total $\mathrm{Fe}$ concentration $[\mathrm{Fe}]=6.2 \times 10^{14} \mathrm{~cm}^{-3}$ is slightly higher than the determined defect concentration for the suggested Fe-related peaks $\left(N_{t}(\mathrm{Fe} 2+\mathrm{Fe} 3)=3.9 \times 10^{14} \mathrm{~cm}^{-3}\right)$, see Table II.

In Ref. 9, Trapaidze et al. also discuss Fe-related peaks in $p$-type $\mathrm{SiC}$ doped with $\mathrm{Al}$. The authors detect two peaks $\left(E_{V}+1.06 \mathrm{eV}\right.$ and $\left.E_{V}+1.35 \mathrm{eV}\right)$, which increase with rising Fe-doses at slightly different activation energies than $\mathrm{Fe} 3\left(E_{V}+0.97 \mathrm{eV}\right)$ and $\mathrm{Fe} 2\left(E_{V}+1.46 \mathrm{eV}\right)$. Additionally, the authors suggest $\mathrm{Fe}-\mathrm{Al}$ pairs as possible origin for their level at $E_{V}+1.06 \mathrm{eV}$ and $\mathrm{Fe}_{i}$ for their level at $E_{V}+1.35 \mathrm{eV}$, respectively. Our samples, in contrast, were unintentionally $p$-doped with a residual background $B$ contamination and SIMS revealed that the Al-concentration in our layers was below the detection limit for Al. Moreover, the Al-bound exciton ${ }^{34}$ was not detected in photoluminescence measurements. However, $\mathrm{B}$ is identified by SIMS $\left([\mathrm{B}]=1.3 \times 10^{15} \mathrm{~cm}^{-3}\right)$ and MCTS, as discussed above. Different doping species will result in different defect levels if a pair formation with Fe occurs; we therefore suggest that the $\mathrm{Fe} 2$ and $\mathrm{Fe} 3$ peaks may be related to $\mathrm{Fe}-\mathrm{B}$ pairs and/or $\mathrm{Fe}_{i}$.

In Figure 3, the energetic positions of all detected levels in the band gap in $n$ - and $p$-type Fe-doped $4 \mathrm{H}-\mathrm{SiC}$ are summarized. DLTS investigations of the reference sample did not detect any deep level in as-grown $n$-type material at the energetic position of $\mathrm{Fe} 1$, thus this level is likely related to Fe. In the lower part of the band gap, there are several observed levels, as mentioned before. The activation energy of the Fe3 level is close to the previously reported h2 level and the level Fe2 aligns with HK4, however the emission rates are too far off to suggest that they originate from the same center. 


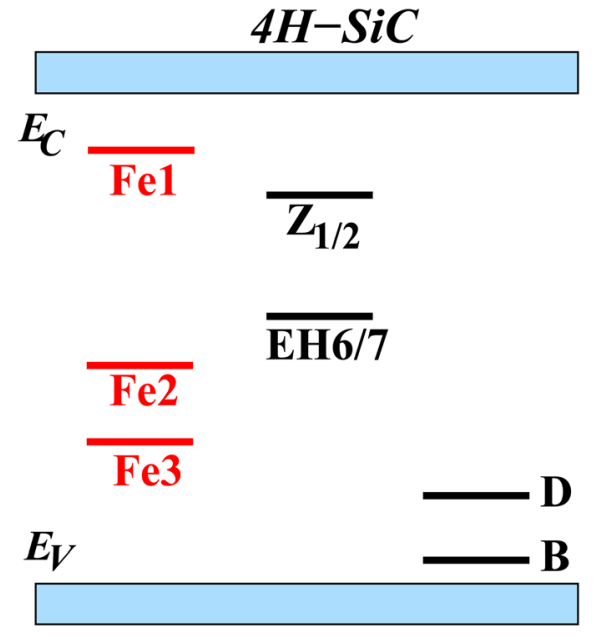

FIG. 3. (Color online) Energetic positions of $\mathrm{Fe}(\mathrm{Fe} 1, \mathrm{Fe} 2$, and $\mathrm{Fe} 3$ ) and $\mathrm{B}$ (B and D-center) related defects as well as intrinsic deep levels $\left(\mathrm{Z}_{1 / 2}\right.$ and EH6/7) in the band gap of the $4 \mathrm{H}-\mathrm{SiC}$.

\section{Temperature dependent electron and hole capture cross sections}

Possible non-radiative capture processes are cascade phonon capture, multi-phonon emission assisted capture (MPE), and capture due to Auger recombination. The three processes show different temperature dependencies. ${ }^{35}$ On the other hand, the capture cross section is increasing exponentially with temperature for MPE $\left(\sigma=\sigma_{\infty} \exp \left(E_{b} / k_{B} T\right)\right)$, the cascade phonon capture shows a $T^{-x}$ dependence. ${ }^{36}$ For an Auger recombination the capture cross section decreases weakly with temperature, whereas a strong dependence on the carrier concentration is observed. ${ }^{35}$ Auger recombination can be ruled out since the interaction of free carriers is unlikely when the carrier density is low, ${ }^{37}$ as in our case.

The electron capture cross section of Fe1, $\sigma_{\text {meas }}$, was determined by changing the DLTS filling pulse width $\left(t_{p}=50 \mathrm{~ns}-20 \mu \mathrm{s}\right)$ over a range of about $\Delta T \approx 30 \mathrm{~K}$ by varying the DLTS time window; $\sigma_{\text {meas }}^{n}$ was found to increase slightly with temperature and thus multi-phonon emission assisted carrier capture takes place, see Figure 4 $\left(\sigma_{\text {meas }}^{n}(\mathrm{Fe} 1)=(3.9 \pm 0.1) \times 10^{-16} \exp \left(-0.038 \mathrm{eV} / k_{B} T\right) \mathrm{cm}^{2}\right)$. The inset of Figure 4 shows a configuration coordinate diagram of the total energy of the lattice and defect versus a generalized coordinate, which clarifies the measured activation barriers for both electron $\left(E_{b}^{n}\right)$ and hole $\left(E_{b}^{p}\right)$ captures. Prior carrier capture, the system is in equilibrium at $Q_{0}$; after the capture process the system favors a different configuration, with a different equilibrium position $Q_{t}$, which is reached under emission of multiple phonons.

For the $p$-type $\mathrm{Fe}$-doped $4 \mathrm{H}$-SiC, the hole capture cross sections, $\sigma_{\text {meas }}^{p}$ of $\mathrm{Fe} 2$ and $\mathrm{Fe} 3$ were studied in the same way by varying the DLTS pulse width $\left(t_{p}=50 \mathrm{~ns}-20 \mu \mathrm{s}\right)$. Also here, the hole capture cross section increases with increasing temperature, see Figure 4. $\sigma_{\text {meas }}^{p}$ were determined by fitting the measured temperature dependent capture cross sections,

$$
\begin{aligned}
& \sigma_{\text {meas }}^{p}(\mathrm{Fe} 2)=(3.8 \pm 0.2) \times 10^{-17} \exp \left(-0.131 \mathrm{eV} / k_{B} T\right) \mathrm{cm}^{2} \\
& \sigma_{\text {meas }}^{p}(\mathrm{Fe} 3)=(1.5 \pm 0.2) \times 10^{-18} \exp \left(-0.180 \mathrm{eV} / k_{B} T\right) \mathrm{cm}^{2}
\end{aligned}
$$

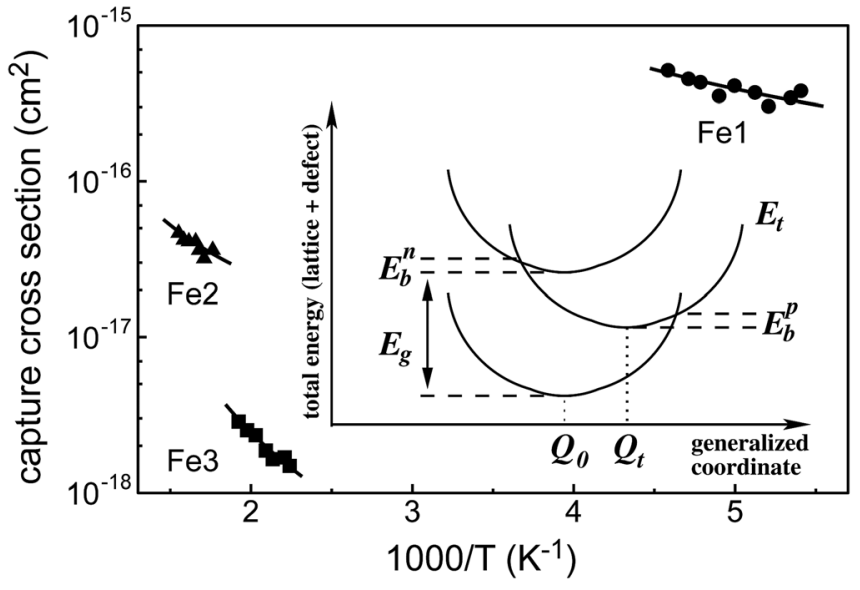

FIG. 4. Temperature dependence of the measured electron (for peak Fe1) and hole (for peaks $\mathrm{Fe} 2$ and Fe3) capture cross sections. The inset shows the coordinate diagram of a multi-phonon emission assisted capture process to a trap level, $E_{t}$, with electron- $\left(E_{b}^{n}\right)$ and hole capture barrier $\left(E_{b}^{p}\right)$.

The thermal barriers $\left(E_{b}^{p}(F e 2)=0.131 \mathrm{eV} \quad\right.$ and $\left.E_{b}^{p}(F e 3)=0.180 \mathrm{eV}\right)$ are higher than in the $n$-type case $\left(E_{b}^{n}(F e 1)=0.038 \mathrm{eV}\right)$. The capture process is achieved by a strong interaction with the lattice, a multi-phonon assisted carrier capture takes place.

\section{CONCLUSION}

In the present study, we have investigated Fe-doped $n$-and $p$-type $4 \mathrm{H}$-SiC. SIMS analysis proved the incorporation of Fe in both $n$ - and $p$-type epilayers. Using DLTS, we observed several possible Fe attributed peaks. In the upper part of the band gap one level, Fe1 is very likely Fe related, and in the lower part of the band gap, there are indications that the detected $\mathrm{Fe} 2$ and $\mathrm{Fe} 3$ are related to $\mathrm{Fe}_{i}$ and $\mathrm{Fe}-\mathrm{B}$ pairs. The temperature dependence of the capture cross sections revealed a multi-phonon emission assisted capturing process for $\mathrm{Fe} 1, \mathrm{Fe} 2$, and $\mathrm{Fe} 3$.

\section{ACKNOWLEDGMENTS}

The Swedish Research Council (VR) and the Swedish Energy Agency are gratefully acknowledged for financial support.

${ }^{1}$ T. Kimoto, T. Nakajima, H. Matsunami, T. Nakata, and M. Inoue, Appl. Phys. Lett. 69, 1113 (1996).

${ }^{2}$ J. R. Jenny, J. Skowronski, W. C. Mitchel, H. M. Hobgood, R. C. Glass, G. Augustine, and R. H. Hopkins, Appl. Phys. Lett. 68, 1963 (1996).

${ }^{3}$ H. K. Song, S. Y. Kwon, H. S. Seo, J. H. Moon, J. H. Yim, J. H. Lee, H. J. Kim, and J. K. Jeong, Appl. Phys. Lett. 89, 152112 (2006).

${ }^{4}$ C. Dupeyrat, A. Declmy, M. Drouet, D. Eyidi, L. Thom, A. Debelle, M. Viret, and F. Ott, Z. Phys. B Condens. Matter 404, 4731 (2009).

${ }^{5}$ H. Pan, Y.-W. Zhang, V. Shenoy, and H. Gao, Appl. Phys. Lett. 96, 192510 (2010).

${ }^{6}$ X. Song, J. F. Michaud, F. Cayrel, M. Zielinski, M. Portail, T. Chassagne, E. Collar, and D. Alquier, Appl. Phys. Lett. 96, 142104 (2010).

${ }^{7}$ A. Zunger, S. Lany, and H. Raebiger, Physics 3, 53 (2010).

${ }^{8}$ P. G. Baranov, I. V. Ilyin, E. N. Mokhov, and V. A. Khramtsov, Semicond. Sci. Technol. 16, 39 (2001).

${ }^{9}$ L. Trapaidze, R. Hollweck, S. Beljakowa, B. Zippelius, H. B. Weber, G. Pensl, and M. Krieger, Mater. Sci. Forum 679-680, 257 (2011). 
${ }^{10}$ T. Tsirimpis, S. Beljakowa, B. Zippelius, H. B. Weber, G. Pensl, M. Krieger, N. Nagasawa, T. Kawahara, N. Hatta, K. Yagi, H. Uchida, M. Kobayashi, and A. Schner, Mater. Sci. Forum 679-680, 265 (2011).

${ }^{11}$ A. A. Istratov, H. Hieslmair, and E. R. Weber, Appl. Phys. A 70, 489 (2000).

${ }^{12}$ H. Kitagawa and S. Tanaka, Physica B 273-274, 416 (1999).

${ }^{13}$ A. A. Istratov, H. Hieslmair, and E. R. Weber, Appl. Phys. A 69, 13 (1999).

${ }^{14}$ M. Syre, E. Monakov, A. Holt, and B. G. Svensson, Phys. Status Solidi C 8, 721 (2011).

${ }^{15}$ H. Pedersen, S. Leone, A. Henry, V. Darakchieva, P. Carlsson, A. Gällström, and E. Janzén, Phys. Status Solidi (RRL) 2, 188 (2008).

${ }^{16}$ H. Pedersen, S. Leone, A. Henry, F. Beyer, V. Darakchieva, and E. Janzén, J. Cryst. Growth 307, 334 (2007).

${ }^{17}$ H. Pedersen, F. Beyer, A. Henry, and E. Janzn, J. Cryst. Growth 311, 3364 (2009).

${ }^{18} \mathrm{P}$. Blood and J. W. Orton, The Electrical Characterization of Semiconductors: Majority Carriers and Electron States (Academic Press, London, 1992).

${ }^{19}$ E.A.G., Evans Analytical Group, Sunnyvale, California, USA.

${ }^{20}$ T. Dalibor, G. Pensl, H. Matsunami, T. Kimoto, W. J. Choyke, A. Schöner, and N. Nordell, Phys. Status Solidi A 162, 199 (1997).

${ }^{21}$ C. Hemmingsson, N. T. Son, O. Kordina, J. P. Bergman, E. Janzén, J. L. Lindström, S. Savage, and N. Nordell, J. Appl. Phys. 81, 6155 (1997).

${ }^{22}$ W. R. Buchwald and N. M. Johnson, J. Appl. Phys. 64, 958 (1988).

${ }^{23}$ C. G. Hemmingsson, N. T. Son, A. Ellison, J. Zhang, and E. Janzén, Phys. Rev. B 58, R10119 (1998).
${ }^{24}$ F. C. Beyer, C. G. Hemmingsson, A. Gällström, S. Leone, H. Pedersen, A. Henry, and E. Janzén, Appl. Phys. Lett. 98, 152104 (2011).

${ }^{25}$ A. P. Zhang, L. B. Rowland, E. B. Kaminsky, V. Tilak, J. C. Grande, J. Teetsov, A. Vertiatchikh, and L. F. Eastman, J. Electron. Mater. 32, 388 (2003).

${ }^{26}$ L. Storasta, J. P. Bergman, E. Janzén, A. Henry, and J. Lu, J. Appl. Phys. 96, 4909 (2004)

${ }^{27}$ M. L. David, G. Alfieri, E. M. Monakhov, A. Hallén, C. Blanchard, B. G. Svensson, and J. F. Barbot, J. Appl. Phys. 95, 4728 (2004).

${ }^{28}$ A. Castaldini, A. Cavallini, L. Rigutti, and F. Nava, Appl. Phys. Lett. 85, 3780 (2004).

${ }^{29}$ A. Castaldini, A. Cavallini, and L. Rigutti, Semicond. Sci. Technol. 21, 724 (2006).

${ }^{30}$ S. Y. Han and J.-L. Lee, Appl. Phys. Lett. 84, 538 (2004).

${ }^{31}$ K. Danno, T. Kimoto, and H. Matsunami, Appl. Phys. Lett. 86, 122104 (2005).

${ }^{32}$ K. Danno and T. Kimoto, Jpn. J. Appl. Phys. 45, L285 (2006).

${ }^{33}$ K. Danno, T. Hori, and T. Kimoto, J. Appl. Phys. 101, 053709 (2007).

${ }^{34}$ L. L. Clemen, R. P. Devaty, M. F. MacMillan, M. Yoganathan, W. J. Choyke, D. J. Larkin, J. A. Powell, J. A. Edmond, and H. S. Kong, Appl. Phys. Lett. 62, 2953 (1993).

${ }^{35}$ C. H. Henry and D. V. Lang, Phys. Rev. B 15, 989 (1977).

${ }^{36}$ M. Lax, Phys. Rev. 119, 1502 (1960).

${ }^{37}$ H. Okushi, Y. Tokumaru, S. Yamasaki, H. Oheda, and K. Tanaka, Phys. Rev. B 25, 4313 (1982). 